OPEN ACCESS

Edited by:

Mohammad Hossein Karimi, Shiraz University of Medical Sciences,

Iran

Reviewed by:

Philippe Lewalle,

Jules Bordet Institute, Belgium

Marit Inngjerdingen,

University of Oslo, Norway

${ }^{*}$ Correspondence:

Benedetto Bruno benedetto.bruno@

nyulangonehealth.org

${ }^{+}$These authors have equally contributed to this work

Specialty section:

This article was submitted to Alloimmunity and Transplantation,

a section of the journal

Frontiers in Immunology

Received: 16 November 2021

Accepted: 29 December 2021

Published: 25 January 2022

Citation:

Lia G, Di Vito C, Bruno S, Tapparo M,

Brunello L, Santoro A, Mariotti J,

Bramanti S, Zaghi E, Calvi M,

Comba L, Fasci M, Giaccone L, Camussi G, Boyle EM, Castagna L, Evangelista A, Mavilio D and Bruno B

(2022) Extracellular Vesicles as Biomarkers of Acute Graft-vs. -Host

Disease After Haploidentical Stem Cell

Transplantation and Post-Transplant

Cyclophosphamide.

Front. Immunol. 12:816231.

doi: 10.3389/fimmu.2021.816231

\section{Extracellular Vesicles as Biomarkers of Acute Graft-vs.-Host Disease After Haploidentical Stem Cell Transplantation and Post-Transplant Cyclophosphamide}

Giuseppe Lia ${ }^{1,2 \dagger}$, Clara Di Vito ${ }^{3,4 \dagger}$, Stefania Bruno ${ }^{5}$, Marta Tapparo ${ }^{5}$, Lucia Brunello ${ }^{1,2}$, Armando Santoro ${ }^{6}$, Jacopo Mariotti ${ }^{6}$, Stefania Bramanti ${ }^{6}$, Elisa Zaghi ${ }^{3}$, Michela Calvi ${ }^{3,4}$, Lorenzo Comba ${ }^{1,2}$, Martina Fasci ${ }^{1,2}$, Luisa Giaccone ${ }^{1,2}$, Giovanni Camussi ${ }^{5}$, Eileen M. Boyle ${ }^{7}$, Luca Castagna ${ }^{6}$, Andrea Evangelista ${ }^{8}$, Domenico Mavilio ${ }^{3,4}$ and Benedetto Bruno ${ }^{2,7 *}$

\begin{abstract}
1 Division of Hematology, Department of Oncology, A.O.U. Città della Salute e della Scienza di Torino, Torino, Italy, ${ }^{2}$ Department of Molecular Biotechnology and Health Sciences, University of Torino, Torino, Italy, ${ }^{3}$ Unit of Clinical and Experimental Immunology, IRCCS Humanitas Research Hospital, Rozzano, Italy, ${ }^{4}$ Department of Medical Biotechnologies and Translational Medicine (BioMeTra), University of Milan, Milan, Italy, ${ }^{5}$ Department of Medical Sciences, Molecular Biotechnology Center, University of Torino, Torino, Italy, ${ }^{6}$ Bone Marrow Transplant Unit, IRCCS Humanitas Research Hospital, Rozzano, Italy, ${ }^{7}$ Division of Hematology and Medical Oncology, New York University Grossman School of Medicine, Perlmutter Cancer Center, New York University (NYU) Langone Health, New York, NY, United States, ${ }^{8}$ Clinical Epidemiology, A.O.U. Città della Salute e della Scienza di Torino, Torino, Italy
\end{abstract}

Even with high-dose post-transplant cyclophosphamide (PT-Cy) which was initially introduced for graft-versus-host disease (GVHD) prevention in the setting of HLA-haploidentical transplantation, both acute and chronic GvHDs remain a major clinical challenge. Despite improvements in the understanding of the pathogenesis of both acute and chronic GvHDs, reliable biomarkers that predict their onset have yet to be identified. We recently studied the potential correlation between extracellular vesicles (EVs) and the onset of acute (a)GVHD in transplant recipients from related and unrelated donors. In the present study, we further investigated the role of the expression profile of membrane proteins and their microRNA (miRNA) cargo (miRNA100, miRNA155, and miRNA194) in predicting the onset of aGvHD in haploidentical transplant recipients with PT-Cy. Thirty-two consecutive patients were included. We evaluated the expression profile of EVs, by flow cytometry, and their miRNA cargo, by realtime PCR, at baseline, prior, and at different time points following transplant. Using logistic regression and Cox proportional hazard models, a significant association between expression profiles of antigens such as CD146, CD31, CD140a, CD120a, CD26, CD144, and CD30 on EVs, and their miRNA cargo with the onset of aGvHD was observed. Moreover, we also investigated a potential correlation between EV expression profile and cargo with plasma biomarkers (e.g., ST2, sTNFR1, and REG3a) that had been associated with aGVHD previously. This analysis showed that the combination of CD146, sTNFR1, and miR100 or miR194 strongly correlated with the onset of aGvHD (AUROC $>0.975$ ). A large prospective multicenter study is currently in progress to validate our findings.

Keywords: extracellular vesicles, biomarkers, acute GvHD, haploidentical, correlation, miRNA 


\section{INTRODUCTION}

Hematopoietic cell transplantation (HCT) represents a potentially curative strategy for several hematological malignancies. In recent years, the use of post-transplant cyclophosphamide (PT-Cy) as graft-vs.-host disease (GvHD) prophylaxis led to a considerable expansion of haploidentical transplants (Haplo-HCT) with remarkable clinical outcomes (1). However, both acute and chronic GvHDs remain life-threatening complications $(2,3)$. To predict their onset and develop preemptive interventions, the identification of reliable biomarkers still represents an unmet need. It is widely assumed that the combination of a profound cytokine imbalance and donor alloreactive T-cells plays a major role in the pathogenesis of acute GvHD (aGvHD) $(3,4)$. Several systemic biomarkers, including micro(mi)RNAs (i.e., miR155, miR100, miR194, miR423, miR199a) (5-9), suppression of tumorigenicity 2 (ST2), tumor necrosis factor receptor 1 (TNFR1), and organspecific biomarkers, such as regenerating islet-derived protein 3 alpha (REG3a), hepatocyte growth factor (HGF), and elafin, have been investigated as potential biomarkers of aGvHD in various biological fluids (10-13). Unfortunately, to date, none of these biomarkers have been able to universally predict either risk or severity of developing GvHD.

Extracellular vesicles (EVs) have recently been reported as a promising group of circulating biological biomarkers (14-16). EVs are cell-derived membranous structures containing different biomolecules, including nucleic acids, proteins, lipids, and carbohydrates. They play a major role in intercellular communication by transferring proteins, bioactive lipids, and miRNA to recipient cells (17-19). Increasing research on EVs has demonstrated that EVs are involved in many pathophysiological processes and that they might be exploited as biomarkers of several pathological conditions (20). Moreover, EVs can be isolated easily from body fluids, including blood and urine, in a minimally invasive manner. Our group recently reported that the expression of CD146, CD31, and CD140a on their surface significantly correlated with the risk of developing acute GvHD in HLA-identical HCT (21). To further investigate the role of EVs as an aGvHD biomarker, we hereby report the same analysis in the setting of Haplo-HCT with PT-Cy. Moreover, given the role of miR100, miR155, and miR194 in endothelial damage, inflammation, and neovascularization which are also key factors in the pathogenesis of aGVHD, we evaluated their expression level in EVs.

\section{MATERIALS AND METHODS}

\section{Patients, Transplant Characteristics, and Graft-vs.-Host Disease}

Thirty-two consecutive patients who underwent a Haplo-HCT from related donors were enrolled at the Bone Marrow Transplant Unit, Humanitas Cancer Center, Humanitas Research Hospital in Rozzano, Milan, Italy. Patients and donors signed an informed consent, and all study procedures were conducted in accordance with the Declaration of Helsinki. Patient, disease, and transplant characteristics are summarized in Table $\mathbf{1}$.
GvHD prophylaxis consisted of PT-Cy $50 \mathrm{mg} / \mathrm{kg}$ on days +3 and +4 , tacrolimus and/or cyclosporin $\mathrm{A}$, and mycophenolate mofetil (MMF) from day +5 post-transplant. Additionally, granulocyte colony-stimulating factor (G-CSF) was started on day +5 . Disease response was defined according to the European Bone Marrow Transplantation (EBMT) Group criteria. Acute GvHD was graded according to Glucksberg score.

\section{Plasma Sample Collection}

Peripheral blood was drawn on lithium-heparin, from both donors and recipients before transplant (day -6) and from the recipients after a median of $0,3,7,14,21,30,45$, and days and 2 , 2.5, and 3 months following transplant. Plasma samples were obtained after mononuclear cell separation by density gradient centrifugation (Lympholyte, Cedarlane, Burlington, Canada) and stored at $-80^{\circ} \mathrm{C}$ until use (22).

\section{Extracellular Vesicle Precipitation and Characterization}

For each sample, $1 \mathrm{ml}$ of plasma was thawed on ice and centrifuged at $2,000 \times \mathrm{g}$ at $4^{\circ} \mathrm{C}$ for $40 \mathrm{~min}$ to remove platelet

TABLE 1 | Patient and transplant characteristics.

\begin{tabular}{|c|c|}
\hline & $\begin{array}{c}\text { Number } \\
(\%)\end{array}$ \\
\hline Patients & 32 \\
\hline Median age, years (range) & $41(21-66)$ \\
\hline Male & 17 (53\%) \\
\hline \multicolumn{2}{|l|}{ DISEASE } \\
\hline Hodgkin lymphoma & 17 (53\%) \\
\hline Non-Hodgkin lymphoma & $11(34 \%)$ \\
\hline Acute lymphoblastic leukemia & $2(6 \%)$ \\
\hline Chronic lymphocytic leukemia & $1(3 \%)$ \\
\hline Acute myeloid leukemia & $1(3 \%)$ \\
\hline \multicolumn{2}{|l|}{ Myeloablative conditioning } \\
\hline TBF & $3 / 32(9 \%)$ \\
\hline \multicolumn{2}{|c|}{$\begin{array}{l}\text { Reduced intensity conditioning (RIC)/non-myeloablative } \\
\text { conditioning }\end{array}$} \\
\hline Baltimore & $\begin{array}{l}22 / 32 \\
(69 \%)\end{array}$ \\
\hline ONC005 & $6 / 32(19) \%$ \\
\hline TBF RIC & $1 / 32(3) \%$ \\
\hline \multicolumn{2}{|l|}{ Stem cell source } \\
\hline Bone marrow & $\begin{array}{l}31 / 32 \\
(97 \%)\end{array}$ \\
\hline Peripheral blood stem cells & $1 / 32(3 \%)$ \\
\hline \multicolumn{2}{|l|}{ GvHD prophylaxis } \\
\hline Pt-Cy + tacrolimus + MMF & $\begin{array}{l}22 / 32 \\
(69 \%)\end{array}$ \\
\hline $\mathrm{Pt}-\mathrm{Cy}+\mathrm{CyA}+\mathrm{MMF}$ & $\begin{array}{l}10 / 32 \\
(31 \%)\end{array}$ \\
\hline aGvHD grades II-IV & 7 (21.88\%) \\
\hline Median day of onset (range) & $41(33-90)$ \\
\hline aGvHD grades III-IV & $1(17 \%)$ \\
\hline
\end{tabular}

TBF, thiotepa (5 mg/ $/ \mathrm{kg}$; days -6, -5) - fludarabine (50 mg/m² ; days -4, -3, -2) - busulfan (30 $\mathrm{mg} / \mathrm{kg}$; days $-4,-3,-2)$; Baltimore = fludarabine $\left(30 \mathrm{mg} / \mathrm{m}^{2}\right.$; days $\left.-6,-5,-4,-3,-2\right)-$ cyclophosphamide (14.5 mg/kg; days -6, -5), total body irradiation (200 cGy), ONCOO5 = thiotepa (5 mg/kg twice a day; day -6) - fludarabine (30 $\mathrm{mg} / \mathrm{m}^{2}$; days -5 ; -4, -3, -2) cyclophosphamide (30 mg/kg; days -5); TBF RIC = thiotepa (5 mg/kg; days -6, -5) fludarabine (50 mg/ $/ \mathrm{m}^{2}$; days -4, -3, -2) - busulfan (3.2 mg/ $\mathrm{kg}$; days -4, -3); PT-Cy = posttransplant cyclophosphamide; $M M F=$ mycophenolic acid; CyA = cyclosporin A. 
contamination. EVs were then precipitated as previously described (21). After precipitation, EVs were resuspended in $150 \mu \mathrm{l}$ of Roswell Park Memorial Institute (RPMI) medium supplemented with penicillin, streptomycin, and amphotericin B, plus $10 \%$ of dimethyl sulfoxide (DMSO), and stored at $-80^{\circ} \mathrm{C}$ until use. EV size and concentration were assessed by nanoparticle tracking (NTA) analysis (21). The presence of EVs on precipitated samples was confirmed by transmission electron microscopy. EVs were left to adhere to 200-mesh Nickel Formvar ${ }^{\circledR}$ carbon-coated grids (Electron Microscopy Sciences) for $10 \mathrm{~min}$. Grids were then washed with phosphate-buffered saline (PBS), fixed with $2.5 \%$ glutaraldehyde containing $2 \%$ sucrose, negatively stained with NanoVan ${ }^{\circledR}$ (Nanoprobes), and observed by JEOL JEM-1400 Flash electron microscope (Tokyo, Japan). The presence and percentage of exosomes in our precipitated EV samples were measured by flow cytometry using CD9 and CD81 phycoerythrin (PE)-conjugated antibodies (Figure 1).

\section{Flow Cytometry Analysis}

EVs were characterized by flow cytometry using fluorescein isothiocyanate (FITC) or phycoerythrin (PE)-conjugated antibodies, investigating the expression of $14 \mathrm{EV}$ membrane proteins (Supplementary Table 1). Mouse non-immune isotypic FITC or PE IgGs (Miltenyi Biotec, Bergisch Gladbach, Germany) were used as negative controls. Incubation of tagged antibodies $(0.8-1.5 \mu \mathrm{l})$ and EVs $\left(3 \times 10^{9}\right.$ particles $)$, flow cytometry acquisition on a Guava Instrument (Guava easyCyte ${ }^{\mathrm{TM}} 8$, Merck Millipore, Billerica, MA, USA), and gate setting were performed as previously described (21).

For each marker, a total of 5,000-10,000 events were acquired at low speed (repeated 2-4 times) to determine a) the mean fluorescence intensity (MFI) and b) the percentage and concentration of positive EVs (Figure $\mathbf{1}$ and Supplementary Figure 2). Concentrations of positive EVs for given markers were obtained by multiplying the frequency of positive events and total EV concentration. Data were analyzed using the guavaSoft InCyte 2.5 program.

\section{miRNA Extraction}

miRNas were extracted from EVs by TRIzol LS (Thermo Fisher Scientific, Waltham, MA, USA) according to the manufacturer's instructions. Briefly, $70 \mu \mathrm{l}$ of EV suspension was diluted in $180 \mu \mathrm{l}$ of PBS ( $\mathrm{pH} 7.4$ ) and lysed by adding $750 \mu \mathrm{l}$ of TRIzol LS. Subsequently, $200 \mu \mathrm{l}$ of chloroform was added and samples were centrifuged at $12,000 \times \mathrm{g}$ at $4^{\circ} \mathrm{C}$ for $15 \mathrm{~min}$ to allow phase separation. The upper aqueous phase was then transferred, and $750 \mu \mathrm{l}$ of $100 \%$ ethanol was added to allow the RNAs precipitation. MiRNAs were then purified by a miRNeasy Mini Kit (Qiagen, Hilden, Germany), according to the manufacturer's instruction. RNA concentrations were assessed using a NanoDrop 2000 spectrophotometer (Thermo Scientific, Waltham, MA, USA).

\section{miRNA Reverse Transcription and Real-Time PCR Quantification}

MiRNAs were reverse transcribed to cDNA using a miScript II RT Kit (Qiagen). Briefly, 60 ng of input RNA from all samples was reverse transcribed at $37^{\circ} \mathrm{C}$ for $1 \mathrm{~h}$ in the presence of 2 units of Bacteroides Heparinase I (NEB, Ipswich, MA, USA) in a final volume of $15 \mu \mathrm{l}(23)$.

The expression of miR100, miR155, miR194 was then assessed by semiquantitative real-time PCR (qRT-PCR) using the miScript SYBR Green PCR Kit (Qiagen). RNU6b and miR92b were used as housekeeping reference genes to normalize qRT-PCR outputs. All samples were run at least in triplicate using $3 \mathrm{ng}$ of cDNA for each reaction in a final volume of $10 \mu \mathrm{l}$. qRT-PCR was performed as follows: $15 \mathrm{~min}$ at $95^{\circ} \mathrm{C} ; 15 \mathrm{~s}$ at $94^{\circ} \mathrm{C}, 30 \mathrm{~s}$ at $55^{\circ} \mathrm{C}, 30 \mathrm{~s}$ at $70^{\circ} \mathrm{C}$ for 52 cycles, and finalized by a dissociation curve with a 5 -s dwell time for each $0.5^{\circ} \mathrm{C}$ increment.

Data were expressed as relative to healthy donor quantification (RQ) using the $\Delta \Delta \mathrm{Ct}$ method. miR92b was used as stable miRNA reference given its lower intra-patient expression variability in comparison to RNU6b (Supplementary Figure 3) (24).

\section{Enzyme-Linked Immunosorbent Assay}

Soluble forms of human TNFR1, ST2, and REG3a were assessed in plasma samples using commercially available sandwich enzyme-linked immunosorbent assays (ELISA; R\&D Systems Europe, Abingdon Science Park, Abingdon, UK). Plasma samples were diluted in $1 \%$ bovine serum albumin in PBS (1:15 for TNFR1, 1:15-1:60 for ST2, and 1:200 for REG3a).

Plasma concentrations of TNFR1, ST2, and REG3a were determined according to the manufacturer's protocol in both donors and recipients before transplant and at different time points post-transplant.

\section{Statistical Analyses}

Cumulative incidences of aGvHD were calculated from the date of transplant to the date of onset. The estimations were performed considering relapse or death from any cause as competing event as described by Gooley et al. (25) Patients alive without GvHD were censored at the last available follow-up time point. The effects of repeated measurements of each marker on incidence of aGvHD were analyzed dividing the follow-up of each patient in a period of 7 days without considering pretransplant measurements and the first week after. Patients were classified by presence/absence of aGvHD during each period. In case of more than one measurement for a given marker in the same 7-day period, the analysis was performed considering the mean value. Thus, the probability of developing aGvHD in each period with respect to marker levels, evaluated as absolute measure and as proportional change from pre-transplant value [expressed as (biomarker value - pre-transplant value)/pretransplant value], was calculated by the logistic regression model (LRM). The effects on aGvHD incidence were reported as standardized odds ratio (OR), indicating the effect for a 1standard deviation (SD) increase for a given variable per 1-point increase (relative increase of $100 \%$ ) and corresponding $\mathrm{p}$ value for statistical significance. Analyses were based on repeated measurements on the same patient; ORs were estimated checking the standard errors with the Huber-White Sandwich Estimator. Moreover, for sensitivity analysis, Cox proportional hazard models $(\mathrm{CM})$ for aGvHD were estimated using $\mathrm{EV}$ 

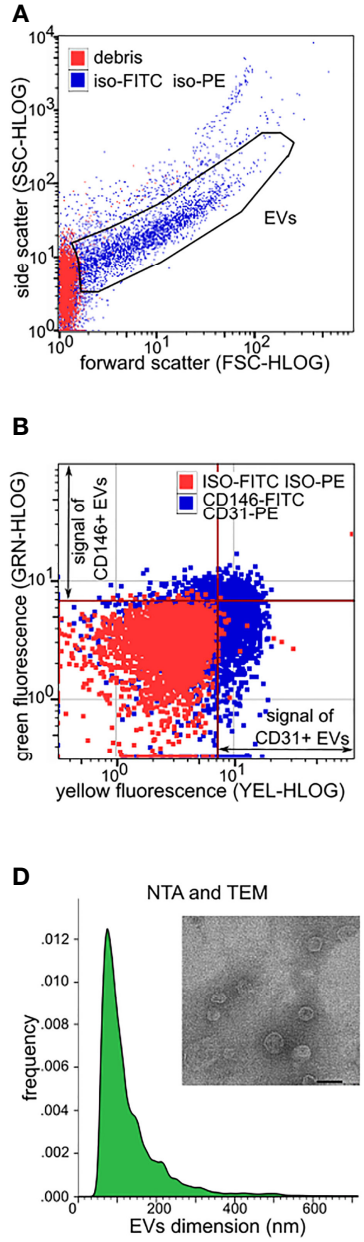
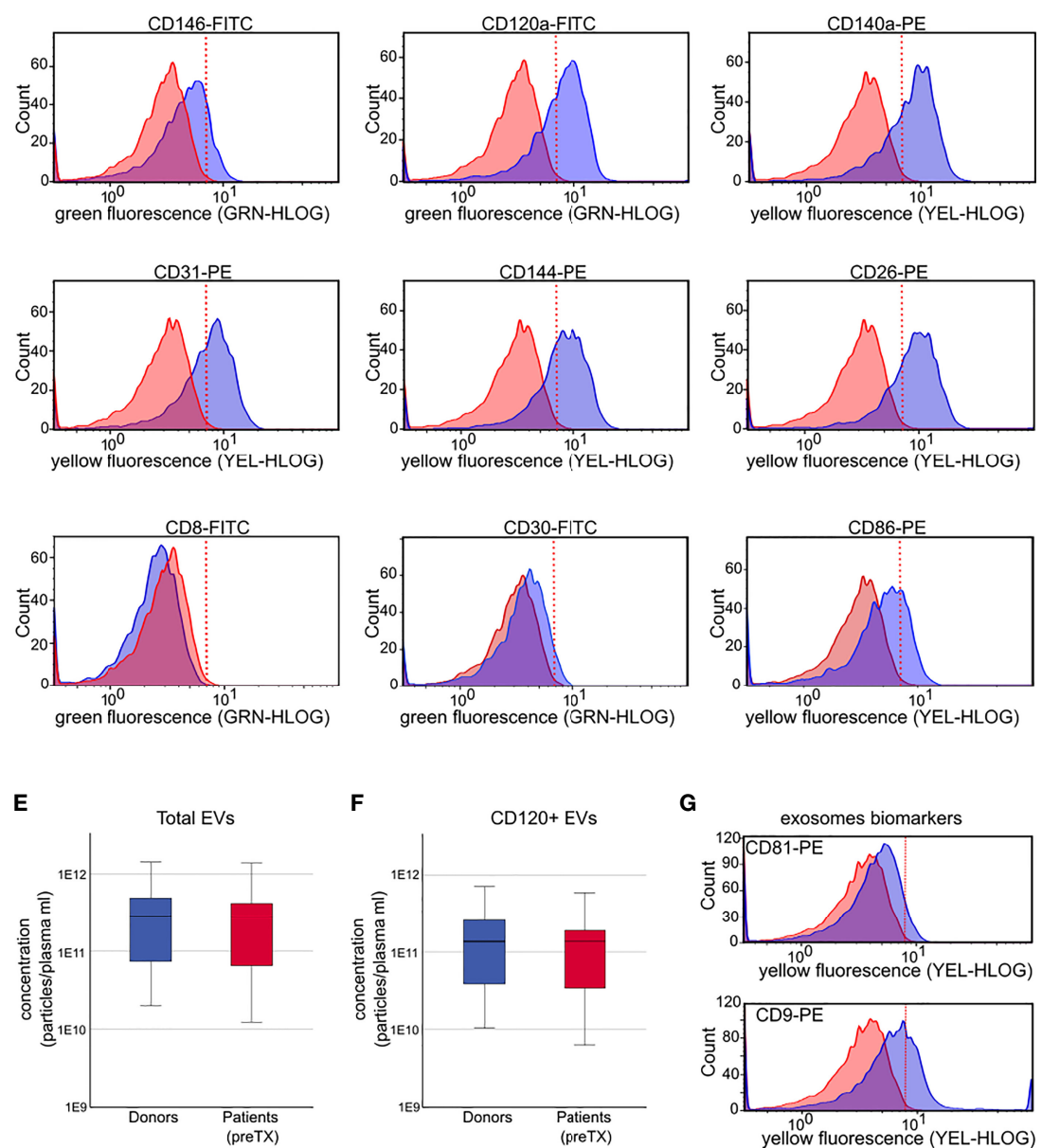

FIGURE 1 | Extracellular vesicle (EV) characterization by light scattering and fluorescence. (A) Forward and side scatter dot plots of EVs analyzed after incubation with non-immune isotypic FITC and PE-IgG (iso-FITC/iso-PE, negative controls, blue dots). Red dots represent debris. (B) Representative fluorescence dot plots showing EV fluorescence after incubation with non-immune isotypic FITC and PE-IgG (negative controls, red dots), and after incubation with anti-CD146-FITC and anti-CD31-PE (blue dots). The red line marks the threshold to discriminate the positive FITC (green fluorescence) and the positive PE fluorescence (yellow fluorescence) signal from the background. (C) Representative histograms showing the shift in fluorescence after incubation of EVs with the indicated antibodies (blue peaks) with respect to isotypic control (FMO, red peaks). (D) Donor EV dimension histograms by nanoparticle tracking analysis. Inset: representative image of EVs detected by transmission electron microscopy (magnification $\times 60,000$; scale bar $50 \mathrm{~nm}$ ). (E, F) Plasma concentration of total EVs (E) and concentration of CD120+ EVs (F) in donors (blue) and in patients prior to transplant (preTX, red). (G) Representative flow cytometry histograms showing the shift in fluorescence after incubation of donor EVs with anti-CD9-PE and anti-CD81-PE (exosomes biomarkers). EVs = gated region; red line marks threshold to discriminate positive florescence signal from background.

parameters at each time point as a time-varying covariate and reporting the hazard ratios (HRs) for a $1-\mathrm{SD}$ increase. The discrimination ability on predicting the aGvHD of single biomarkers was evaluated by performing univariable logistic regression models including as independent variable the repeated measurements within the 100-day period of each marker and estimating the univariable area under the receiver operating characteristics (AUROCs). Multivariable models were then estimated to include most predictive markers performing a backward selection by Akaike information criterion selecting a maximum of three biomarkers due to the small number of aGVHD events. Correlation between markers was measured using the Spearman correlation coefficient, and markers most correlated $(r>0.30)$ were included in the models. Finally, for each model, multivariable AUROCs were estimated. Due to repeated measures in the same patient, standard errors of ORs were adjusted using the Huber-White sandwich estimator. All statistical analyses were performed using STATA 15 (StataCorp LP) and SPSS Statistics 25 (IBM SPSS Statistics).

\section{RESULTS}

\section{Acute GvHD}

Acute GvHD requiring systemic therapy was observed in $7 / 32$ $(22 \%)$ of patients with a median day of onset at +41 (range $+33-$ 
+90) (Table 1). The cumulative incidence of grade II-IV aGvHD at day 100 was $21.9 \%$ (95\% confidence interval (CI): 9.6-37.2\%) (Supplementary Figure 1).

\section{EV Characterization and Correlation With aGvHD}

Fluorescence-CD146 fluorescence change was significantly associated with increased risk of aGvHD by both logistic regression and Cox regression models (OR $2.93 \mathrm{p}<0.001$, and HR $2.69 \mathrm{p}=0.009$, respectively). CD30 fluorescence change was associated with an increased risk of aGVHD only by logistic regression (OR $1.58 \mathrm{p}=0.042$ ). Even though CD25 fluorescence was associated with increased risk of aGvHD, its significance should be considered minimal given the overall very low fluorescence levels of this marker (Table 2).

Proportional concentration change-proportional concentration changes in total EVs (OR 0.53, p = 0.01) and in CD120a (OR 0.58, p = 0.018), CD140a (OR 0.55, p = 0.013), CD26 (OR 0.59, p $=0.017), \mathrm{CD} 31(\mathrm{OR} 0.62, \mathrm{p}=0.047)$, and CD144 (OR 0.70, $\mathrm{p}=$ $0.034)$ were significantly associated with decreased risk of aGvHD (Table 2). Moreover, proportional concentration changes in CD30 were associated with increased risk of
aGvHD (OR 1.40, p = 0.051). By contrast, we did not observe any correlation between CD44, CD106, KRT18, CD86, CD8, and CD138 and aGvHD (Table 2). Our findings also showed that these changes were detectable several weeks before the onset of aGvHD (Figure 2).

\section{miRNA Quantification and Correlation With aGVHD}

Expression changes of miR100 (OR $3.90 \mathrm{p}<.001, \mathrm{HR} 2.63, \mathrm{p}=$ 0.001 ), miR155 (OR 1.84, $\mathrm{p}=0.008$, HR 2.43, $\mathrm{p}=0.002$ ), and miR194 (OR $2.68 \mathrm{p}<0.001, \mathrm{HR} 2.99, \mathrm{p}=0.001$ ) were correlated with increased risk of developing aGVHD by both logistic regression and Cox regression models (Table 3A). Moreover, proportional expression change analyses showed that all three miRNAs significantly increased before aGVHD onset (Figure 3).

\section{Plasma Level Measurement of Soluble Biomarkers and Correlation With aGVHD}

The absolute concentration $(\mathrm{ng} / \mathrm{ml})$ and concentration change of sTNFR1 (OR 1.47, $\mathrm{p}=0.041$, and HR 1.42, $\mathrm{p}=0.005$, respectively) were significantly associated with increased risk of aGVHD whereas a trend was observed with ST2 (OR $1.55 \mathrm{p}=0.058, \mathrm{HR}$

TABLE 2 | Association between EV surface biomarker level and aGvHD.

\begin{tabular}{|c|c|c|c|c|c|c|c|c|c|}
\hline \multirow[t]{3}{*}{ Marker } & \multirow[t]{3}{*}{ Type } & \multicolumn{4}{|c|}{ Logistic regression } & \multicolumn{4}{|c|}{ Cox model } \\
\hline & & \multicolumn{2}{|c|}{ Change } & \multicolumn{2}{|c|}{ Absolute } & \multicolumn{2}{|c|}{ Change } & \multicolumn{2}{|c|}{ Absolute } \\
\hline & & OR & $\mathbf{p}$ & OR & $\mathbf{p}$ & HR & $\mathbf{p}$ & HR & $\mathbf{p}$ \\
\hline Total EV conc. & & .53 & .01 & .70 & .045 & .83 & .465 & 1.43 & .407 \\
\hline \multirow[t]{2}{*}{ CD120a } & Fluo. & 1.50 & .193 & 1.33 & .026 & 1.14 & .632 & .83 & .645 \\
\hline & Conc. & .58 & .018 & .76 & .129 & .89 & .632 & 1.50 & .309 \\
\hline \multirow[t]{2}{*}{ CD140a } & Fluo. & 1.12 & .627 & 1.05 & .685 & .90 & .688 & .75 & .5 \\
\hline & Conc. & .55 & .013 & .73 & .066 & .80 & .374 & 1.29 & .555 \\
\hline \multirow[t]{2}{*}{ CD44 } & Fluo. & .80 & .508 & .89 & .38 & 1.17 & .544 & 1.53 & .25 \\
\hline & Conc. & .71 & .194 & .73 & .068 & 1.21 & .469 & 1.87 & .083 \\
\hline \multirow[t]{2}{*}{ CD26 } & Fluo. & 1.12 & .642 & 1.06 & .575 & 1.18 & .501 & 1.18 & .643 \\
\hline & Conc. & .59 & .017 & .74 & .065 & .91 & .694 & 1.61 & .264 \\
\hline \multirow[t]{2}{*}{ CD146 } & Fluo. & 2.93 & $<.001$ & 1.25 & .048 & 2.69 & .009 & 1.26 & .586 \\
\hline & Conc. & .58 & .096 & .76 & .176 & .80 & .423 & 1.12 & .76 \\
\hline \multirow[t]{2}{*}{ CD31 } & Fluo. & .92 & .656 & .97 & .825 & .89 & .636 & .87 & .735 \\
\hline & Conc. & .62 & .047 & .83 & .288 & .81 & .453 & 1.37 & .461 \\
\hline \multirow[t]{2}{*}{ CD106 } & Fluo. & 1.21 & .48 & 1.07 & .671 & 1.34 & .296 & 1.45 & .321 \\
\hline & Conc. & .72 & .133 & .74 & .125 & .99 & .977 & 1.61 & .228 \\
\hline \multirow[t]{2}{*}{ KRT18 } & Fluo. & 1.23 & .454 & 1.04 & .729 & 1.20 & .474 & 1.01 & .981 \\
\hline & Conc. & .92 & .677 & .88 & .483 & 1.12 & .662 & 1.45 & .364 \\
\hline \multirow[t]{2}{*}{ CD30 } & Fluo. & 1.58 & .042 & 1.12 & .37 & 1.53 & .185 & 1.02 & .969 \\
\hline & Conc. & 1.40 & .051 & .98 & .894 & 2.37 & .018 & 2.79 & .029 \\
\hline \multirow[t]{2}{*}{ CD144 } & Fluo. & .92 & .691 & 1.05 & .696 & .81 & .433 & .90 & .793 \\
\hline & Conc. & .70 & .034 & .48 & .004 & 1.52 & .322 & .75 & .291 \\
\hline \multirow[t]{2}{*}{ CD25 } & Fluo. & 1.87 & .046 & .94 & .588 & 1.93 & .044 & 1.18 & .725 \\
\hline & Conc. & 1.07 & .793 & 1.05 & .785 & 1.43 & .198 & .88 & .796 \\
\hline \multirow[t]{2}{*}{ CD86 } & Fluo. & 1.17 & .464 & .97 & .876 & 1.20 & .455 & .93 & .895 \\
\hline & Conc. & .76 & .264 & .88 & .37 & .79 & .379 & .88 & .808 \\
\hline \multirow[t]{2}{*}{ CD8 } & Fluo. & .88 & .578 & 1.15 & .277 & 1.15 & .55 & .98 & .955 \\
\hline & Conc. & .79 & .211 & 1.09 & .545 & 1.25 & .418 & .58 & .175 \\
\hline \multirow[t]{2}{*}{ CD138 } & Fluo. & .90 & .762 & .93 & .695 & .99 & .977 & 1.09 & .852 \\
\hline & Conc. & .64 & .066 & .72 & .054 & .96 & .881 & 1.51 & .336 \\
\hline
\end{tabular}

EV, extracellular vesicle; FLUO., fluorescence; HR, hazard ratio; OR, odd ratio; CONC., concentration of positive EVs (particles/plasma ml).

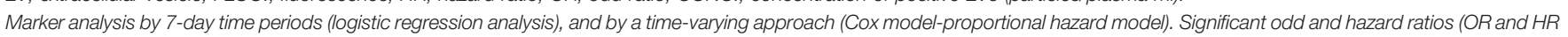
respectively) are in bold. 


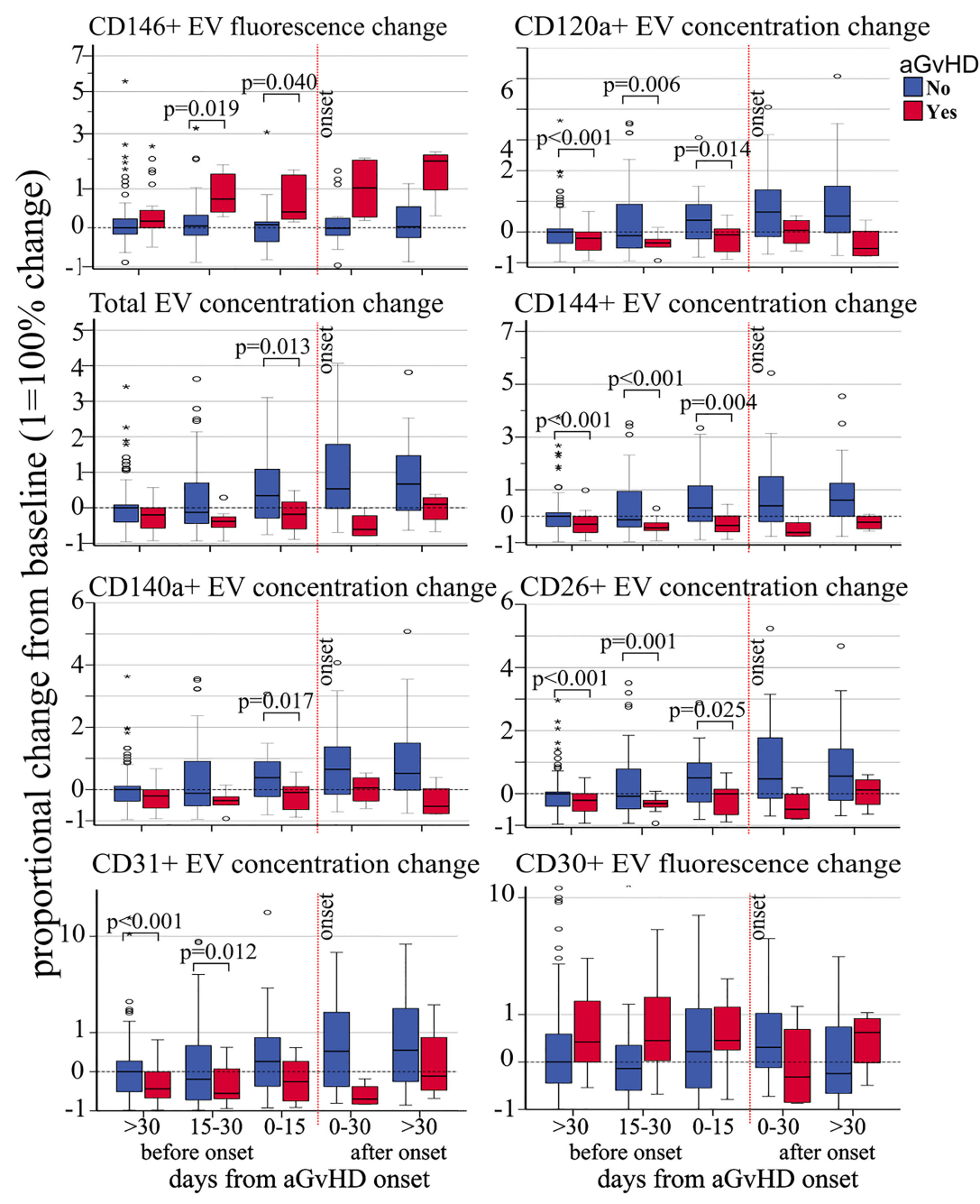

FIGURE 2 | Impact of acute GVHD onset on the kinetics of EV membrane protein expression. Proportional change of fluorescence levels of CD146, total EV

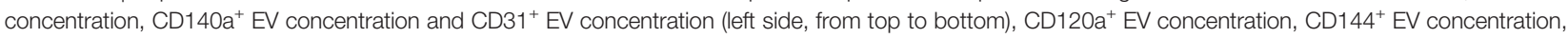
$\mathrm{CD}_{26}{ }^{+}$EV concentration, and fluorescence levels of CD30 from precipitated EVs at different time points before and after aGvHD onset and compared to the pretransplant baseline values. Dashed black line: pre-transplant levels; dashed red line: time of aGvHD onset; circle and star dots represent outliers (>1.5 box length from median) and extreme values (>3 box length from median), respectively. Significant mean differences before the onset ( $p \leq 0.05)$ between patients with aGvHD (red) and without (blue) are indicated.

1.64, $\mathrm{p}=0.053$ ) (Table 3B). No association was observed between REG3a and aGvHD. Moreover, the mean plasmatic concentrations and concentration changes of ST2 and sTNFR1 from day+15 were significantly different in patients with or without aGvHD (Figures 4 and Supplementary Figure 4).

\section{Biomarker Performance}

AUROC curves showed that miR100 and miR194 displayed excellent discriminating performance in separating patients with or without aGvHD (individual AUROC 0.923 and 0.91, respectively) and that CD146 had good performance (AUROC 0.858 ), whereas the other biomarkers that correlated with aGVHD had either poor or fair performance (Figures 5A, B). Based on the Akaike information criteria, the combination of
CD146 and CD144 among the EV membrane proteins, and miR100 and miR194, had high multivariate AUROC, 0.922 and 0.970 , respectively (Figures $\mathbf{5 C}, \mathbf{D}$ ). Two triplet combinations, CD146, miR100, sTNFR1 (combination 1) and CD146, miR194, sTNFR1 (combination 2), (Figures 5E, F) showed the highest AUROC, 0.987 and 0.975, respectively, and allowed to better discriminate patients with or without aGvHD (Figures 5G, H).

\section{DISCUSSION}

Biomarkers that could reliably predict the onset of aGvHD and ensure preemptive interventions are lacking, meaning that diagnosis and treatment rely on clinical signs and symptoms 
TABLE 3 | Association between acute GVHD and EV-derived miRNAs and plasmatic biomarker levels.

A

\begin{tabular}{|c|c|c|c|c|c|c|c|c|}
\hline $\begin{array}{l}\text { Marker } \\
\text { miRNA EV }\end{array}$ & \multicolumn{4}{|c|}{ Logistic regression } & \multicolumn{4}{|c|}{ Cox model } \\
\hline miR100 & 3.90 & $<.001$ & 1.84 & $<.001$ & 2.63 & .001 & 2.61 & .014 \\
\hline miR155 & 1.84 & .008 & 1.41 & .012 & 2.43 & .002 & 2.93 & .01 \\
\hline miR194 & 2.68 & $<.001$ & 1.39 & .013 & 2.99 & .001 & 2.24 & .022 \\
\hline \multirow[t]{2}{*}{ Plasma proteins } & \multicolumn{2}{|c|}{ Change } & \multicolumn{2}{|c|}{ Absolute } & \multicolumn{2}{|c|}{ Change } & \multicolumn{2}{|c|}{ Absolute } \\
\hline & OR & $\mathbf{p}$ & OR & $\mathbf{p}$ & HR & $p$ & HR & $p$ \\
\hline ST2 & 1.04 & .227 & 1.55 & .058 & 1.03 & .156 & 1.64 & .053 \\
\hline sTNFR1 & 1.47 & .041 & 1.56 & .151 & 1.42 & .005 & 1.41 & .117 \\
\hline REG3a & .77 & .086 & 1.17 & .425 & .89 & .636 & 1.18 & .446 \\
\hline
\end{tabular}

EV, extracellular vesicle; $H R$, hazard ratio; OR, odd ratio.

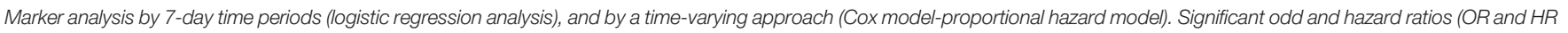
respectively) are in bold.

and tissue biopsies only. Although several molecules/proteins have been investigated $(16,21,26-28)$, in the present study, we evaluated the antigenic profile and miRNA cargo of EVs in the setting of Haplo-HCT using PT-Cy as GvHD prophylaxis.

Overall, we confirm that the risk of developing aGvHD was directly associated with CD146 expression and inversely correlated with total EV concentration and CD31 and CD140a concentrations. CD146 (or melanoma cell adhesion molecule) is a marker of activated endothelial cells, also expressed by CCR5+ T helper 17 (Th17) cells which expand during gastrointestinal aGVHD (29, 30). Moreover, this T-cell population plays an important role in many autoimmune diseases and inflammatory conditions $(31,32)$. CD31 (or platelet/EC adhesion molecule) is also a marker of endothelial activation. CD31 prevents lymphocyte hyperreactivity by increasing the activation threshold of the T-cell receptor (33). Its immuneregulatory role has been clearly demonstrated in murine models where CD31-deficient mice show a pronounced tumor rejection and excessive immune reactivity $(34,35)$. Decreased levels of CD31 in patients with aGvHD may indicate the loss of its protective role against inflammation and detrimental immunological attacks. We also observed a parallel reduction of the EV concentration of CD140a, also known as plateletderived growth factor receptor-alpha (PDGFR- $\alpha$ ), which is instrumental in the migration of fibroblasts and wound healing (36). Pro-inflammatory tumor necrosis factor-alpha (TNF- $\alpha$ ) levels are usually higher in patients with aGvHD (37) and play a pivotal role in both initiating and amplifying aGvHD (38). TNF$\alpha$ also decreases the expression of PDGFR- $\alpha$ after fibroblast injury, and its increased levels during aGvHD could consequently reduce fibroblast activation and tissue recovery (39). Interestingly, we observed that VE-cadherin, also known as CD144, is downregulated, which could be correlated with the increased TNF- $\alpha$ levels observed before $\operatorname{aGvHD}(40,41)$. Increased TNF- $\alpha$ during aGvHD promotes vascular permeability by internalization and degradation of VEcadherin, a calcium-dependent transmembrane cell-cell adhesion molecule, which regulates the formation of adherent junctions between endothelial cells, thus ensuring the physiological permeability and endothelial structure (42-45). We also investigated the EV surface expression of CD120a and its circulating soluble form TNFR1 (46). Increased levels of plasmatic sTNFR1 were shown to be associated with aGvHD (10, 47-49). This could result from the increased activity of the receptor sheddase (i.e., TACE) which proteolytically cleaves the TNFR1 ectodomain (50). Moreover, the increased TNFR1 sheddase activity may partly explain our observation that the concentration of CD120a ${ }^{+}$EVs is reduced in aGvHD (51). All these findings are highly suggestive of endothelial activation.

Significant concentration changes of antigen expression indicating $\mathrm{T}$-cell activation were also observed before the onset of aGvHD. CD30 is a type 1 transmembrane receptor of the TNF/nerve growth factor receptor family (TNFRSF8). It acts as a co-stimulatory molecule in T-cell responses and identifies/ defines proliferating $\mathrm{T}$-cell populations induced by allogeneic antigens (52). We observed a significant increase of CD30 in patients developing aGvHD as previously reported (52-54). By contrast, we observed a decreased level of circulating CD26. CD26, also known as dipeptidyl peptidase IV (DPPIV), is a cell surface glycoprotein enzyme associated with immune regulation, signal transduction, and apoptosis of several cell types (55). CD26 has been also described as a marker of T-cell activation and as an important regulator of inflammation (56-59). It accumulates in inflamed tissues and in target organs of aGvHD $(60,61)$. This may explain in part why its expression on EVs is reduced during aGVHD as seen in several autoimmune and other inflammatory conditions $(62,63)$.

The miRNA cargo of EVs is pivotal for their functions in both physiological and pathological conditions. In particular, we evaluated miR100, miR155, and miR194, given their association with inflammatory conditions and aGvHD, although their expression levels in EVs have not yet been explored. MiR100 has been described as an important player in regulating the inflammatory neovascularization during GvHD (8). In our 


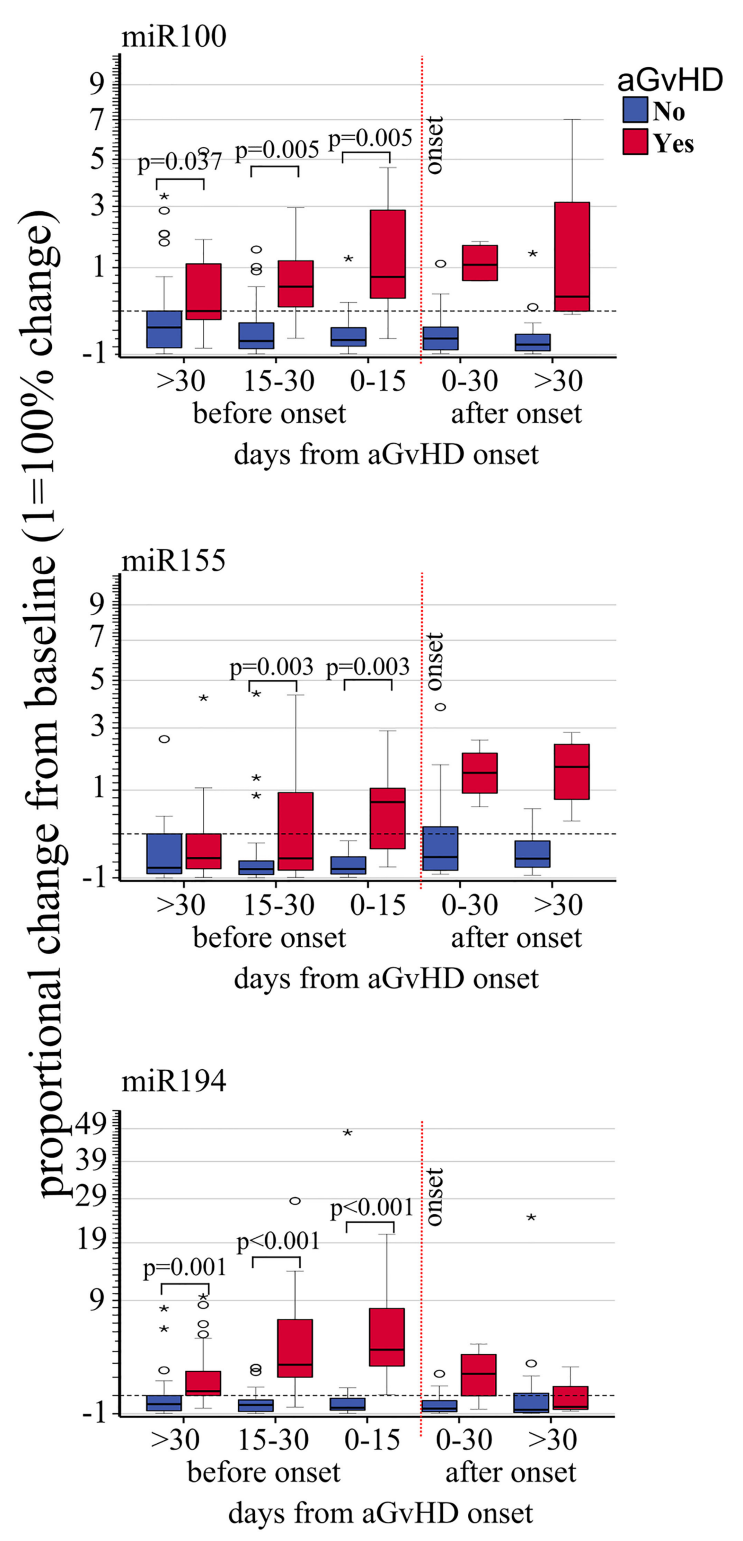

FIGURE 3 | Impact of acute GVHD onset on the kinetics of EV miRNA. Proportional change of miR100, miR155, and miR194 (from top to bottom) quantified by real-rime PCR from precipitated EVs at different time points before and after aGvHD onset and compared to the pre-transplant baseline values. Dash black line: pre-transplant levels; dashed red line: time of aGvHD onset; circle and star dots represent outliers (>1.5 box length from median) and extreme values ( $>3$ box length from median), respectively. Significant mean differences before the onset $(p \leq 0.05)$ between patients with aGvHD (red) and without (blue) are indicated.

patient cohort, the miR100 cargo gradually increased after transplant until the onset of aGvHD. However, its absolute levels remained lower compared to healthy donors and patients without aGvHD (Supplementary Figure 5). MiR155 is a critical regulator of inflammation and of innate and adaptive immune responses $(64,65)$. It has been reported that miR155 modulates aGvHD by driving a proinflammatory Th1 phenotype and by
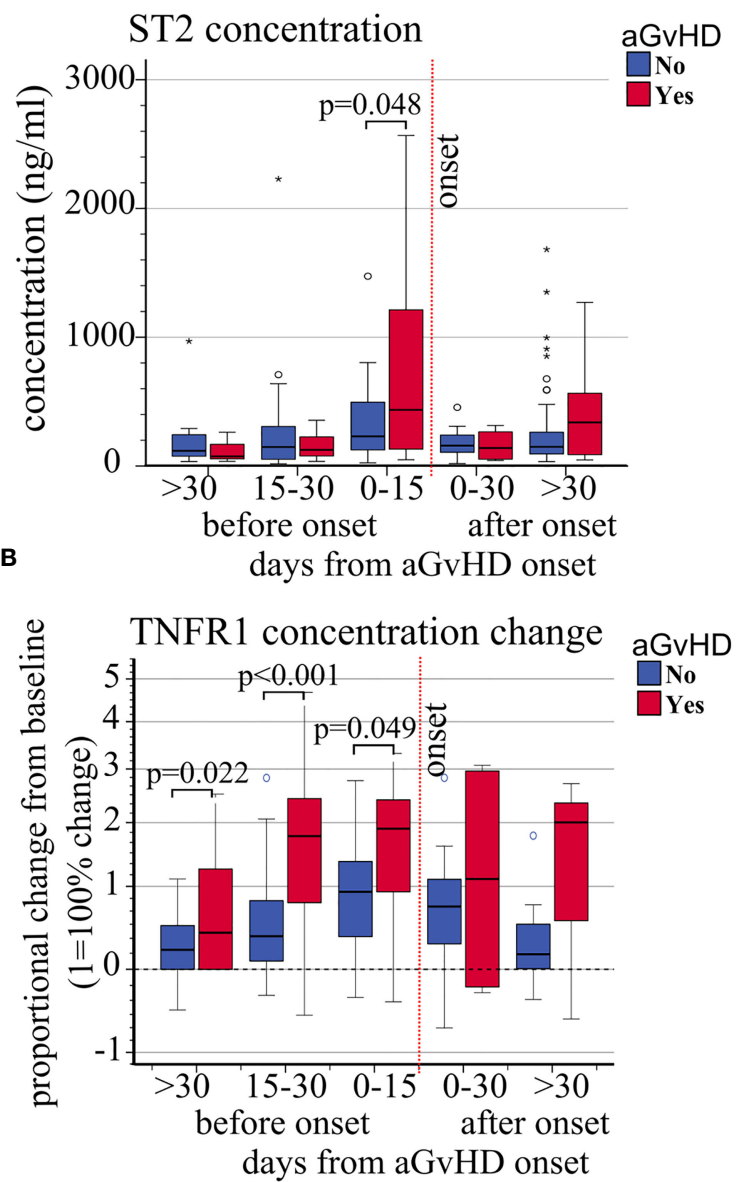

C

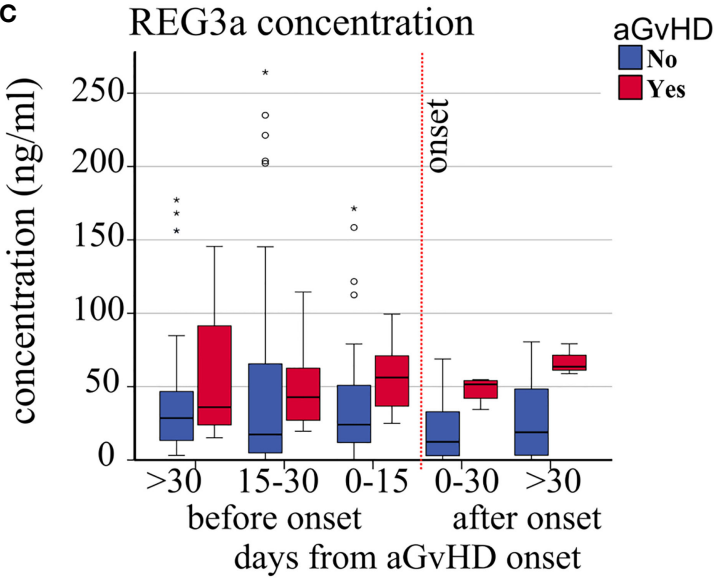

FIGURE 4 | Impact of aGVHD onset on the circulating levels of ST2, sTNFR1, and REG3a. Variations of (A) absolute ST2 plasma level concentrations (ng/ml), (B) STNFR1 relative plasma concentrations, and (C) absolute REG3a plasma level concentrations $(\mathrm{ng} / \mathrm{ml})$ from pre-transplant baseline levels, in patients with (red) and without (blue) aGvHD at different time points before and after aGvHD onset. Dashed black line: pre-transplant levels; dashed red line: time of aGvHD onset; circle and star-shaped dots represent outliers ( $>1.5$ box length from median) and extreme values ( $>3$ box length from median), respectively. Significant mean differences before the onset ( $p \leq 0.05$ ) between patients with $\mathrm{aGvHD}$ (red) and without (blue) are indicated. 
facilitating T-cell expansion, migration, and effector functions (64). Moreover, miR155 is upregulated in donor-derived T-cells in both preclinical mouse models and patients with GvHD. Its downmodulation, with synthetic anti-miR155, decreased aGvHD severity and prolonged survival in mice (5). MiR194 has been found significantly upregulated in patients who would later develop aGvHD. Of note, pathway prediction analyses suggest that these miRNAs regulate critical pathways in aGvHD pathogenesis, such as JAK-STAT, CXCL3, and TGF $\beta$ signaling. They could potentially become therapeutical targets (6). Our findings confirm their potential pivotal role in the development of aGvHD after haploidentical transplantation.

Plasma concentrations of sTNFR1, ST2, and REG3a have been extensively studied (66). We confirm previous findings showing the correlation of ST2 and sTNFR1 with aGvHD. We did not observe any correlation of REG3a. This, however, is likely due to the fact that only one of our patients developed gastrointestinal aGvHD. Finally, our ROC analysis showed that three of the studied biomarkers (miR100, miR194, and CD146) showed excellent or good performance ( $\mathrm{ROC}>0.8$ ). By combining the most informative biomarkers, specificity, predictability, and diagnostic performance could increase. Combinations of CD146 fluorescence and CD144 concentration or miR100 and miR194 represent the minimal combinations that improve the diagnostic performance (multivariate ROC > 0.92). Combinations of plasma levels of sTNFR1, fluorescence of CD146, and miR100 or miR194 were the best combinations that significantly improved the
A

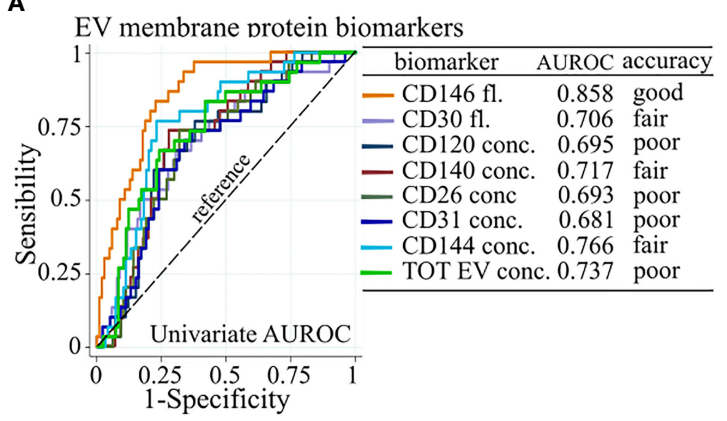

B

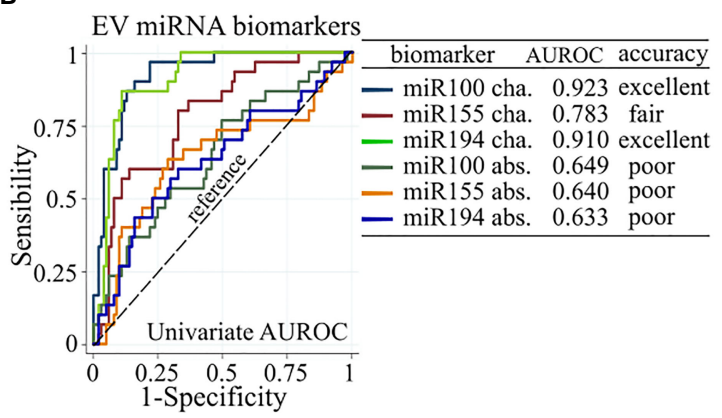

E
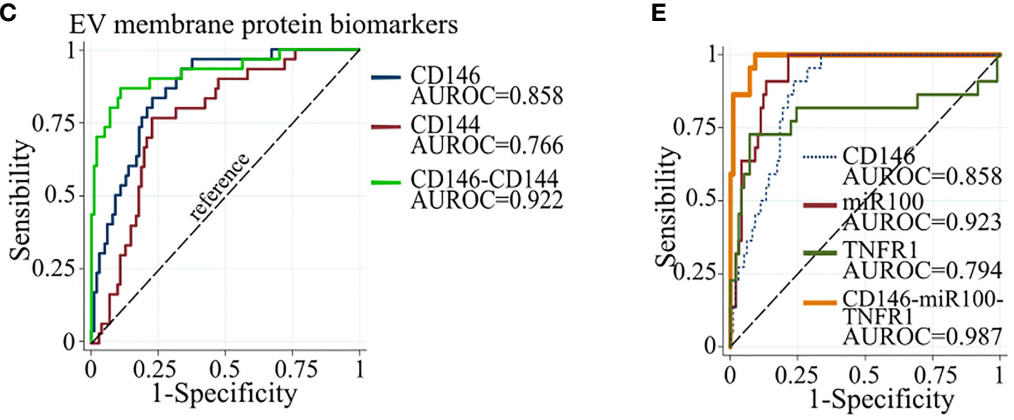

D EV miRNA biomarkers

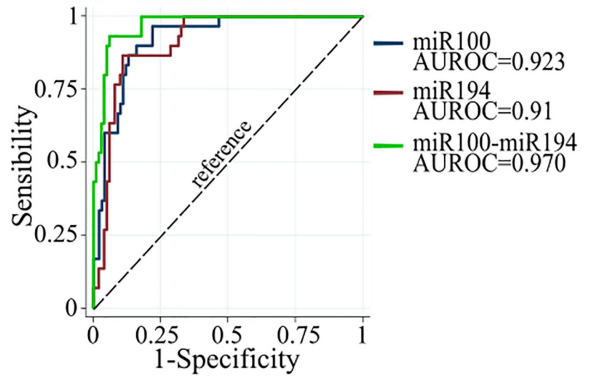

$\mathbf{F}$

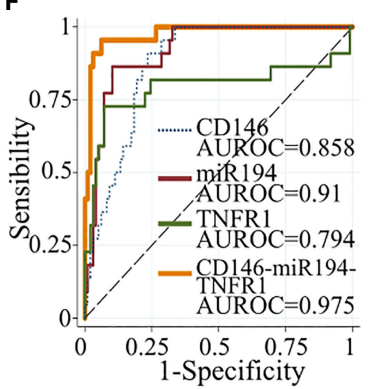

G

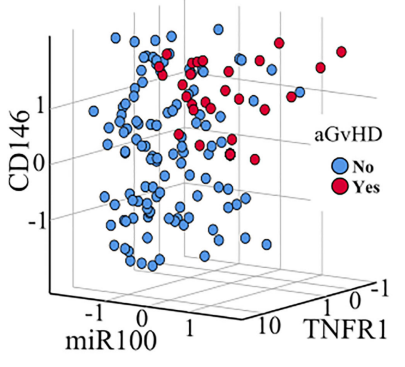

H

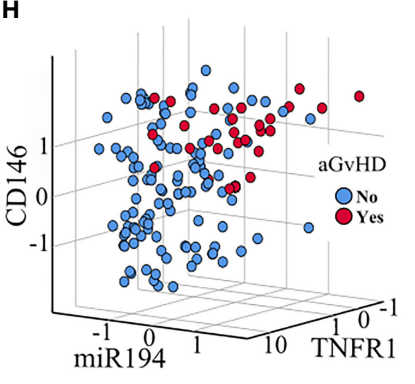

FIGURE 5 | Biomarker combination improves aGvHD prediction. Individual AUROC curve analysis of aGVHD diagnostic performance of (A) EV membrane protein and (B) EV miRNA biomarkers. Individual and multivariate AUROC curve analysis of aGvHD diagnostic performance of (C) CD146 and CD144; (D) miR100 and miR194; (E) CD146, miR100, and sTNFR1; and (F) CD146, miR194, and sTNFR1. AUROC, area under the receiver operating characteristics; dot line, reference line; Fl., fluorescence; conc., concentration; cha., proportional change from basal; abs., absolute value. Three-D scatter plot of standardized proportional change from baseline of (G) CD146 fluorescence, miR100 expression, and sTNFR1 plasma concentration, and of (H) CD146 fluorescence, miR194 expression, and sTNFR1 plasma concentration, in patients with (red) and without (blue) aGvHD. 
diagnostic performance (multivariate $\mathrm{ROC}>0.975$ ) in discriminating patients with and without aGvHD.

Reproducibility and standardization are key to the development of clinically applicable biomarkers. Different methods of EV isolation and characterization may be employed. We used PEG precipitation to isolate EVs from our samples given the volume of starting material $(<1 \mathrm{ml})$. Importantly, our analyses can be carried out in $24-48 \mathrm{~h}$. Although ultracentrifugation techniques may be considered the gold standard for EV purification, they would be more difficult to standardize and be more expensive to run in a clinical laboratory (67-69).

Although our present observations are consistent with our previous findings (21), our cohort remains small in size, with relatively few cases of aGvHD, most of them affecting only the skin and being low in grade (one case III-IV aGvHD only). However, to further confirm our findings and to validate our model, a large multicenter prospective study including patients with different hematological malignancies and transplanted from different donor types has been designed and currently accruing. In summary, our report indicates a turbulence of significant dynamic changes in surface markers and miRNA cargo in plasma EVs that may specifically underlie events that precede the onset of aGvHD. They appear to mainly express endothelial injury and T-cell activation. Furthermore, our biomarker performance analyses suggest that combinations of EVs with other plasma biomarkers may reliably identify patients with incipient aGvHD.

\section{DATA AVAILABILITY STATEMENT}

The raw data supporting the conclusions of this article will be made available on request from the corresponding author.

\section{REFERENCES}

1. McCurdy SR, Luznik L. How We Perform Haploidentical Stem Cell Transplantation With Posttransplant Cyclophosphamide. Blood (2019) 134:1802-10. doi: 10.1182/blood.2019001323

2. Reddy P, Ferrara JL. Immunobiology of Acute Graft-Versus-Host Disease. Blood Rev (2003) 17:187-94. doi: 10.1016/S0268-960X(03)00009-2

3. Zeiser R, Blazar BR. Pathophysiology of Chronic Graft-Versus-Host Disease and Therapeutic Targets. N Engl J Med (2017) 377:2565-79. doi: 10.1056/ NEJMra1703472

4. Zeiser R. Advances in Understanding the Pathogenesis of Graft-Versus-Host Disease. Br J Haematol (2019) 187:563-72. doi: 10.1111/bjh.16190

5. Ranganathan P, Heaphy CEA, Costinean S, Stauffer N, Na C, Hamadani M, et al. Regulation of Acute Graft-Versus-Host Disease by microRNA-155. Blood (2012) 119:4786-97. doi: 10.1182/blood-2011-10-387522

6. Gimondi S, Dugo M, Vendramin A, Bermema A, Biancon G, Cavané A, et al. Circulating miRNA Panel for Prediction of Acute Graft-Versus-Host Disease in Lymphoma Patients Undergoing Matched Unrelated Hematopoietic Stem Cell Transplantation. Exp Hematol (2016) 44:624-34.e1. doi: 10.1016/ j.exphem.2016.03.005

7. Crossland RE, Norden J, Kralj Juric M, Pearce KF, Lendrem C, Bibby LA, et al. Serum and Extracellular Vesicle MicroRNAs miR-423, miR-199, and miR-93* As Biomarkers for Acute Graft-Versus-Host Disease. Front Immunol (2017) 8:1446. doi: 10.3389/fimmu.2017.01446

8. Leonhardt F, Grundmann S, Behe M, Bluhm F, Dumont RA, Braun F, et al. Inflammatory Neovascularization During Graft-Versus-Host Disease Is

\section{AUTHOR CONTRIBUTIONS}

$\mathrm{BB}, \mathrm{DM}$, and GC designed the study. GL, LB, CDV, and BB wrote the report. $\mathrm{BB}$ supervised the conduction of the study and data analyses. SBru, BB, and DM supervised the laboratory procedures. AS, JM, SBra, LCa, EMB and LG supervised the data collection, analyzed the data, and reviewed and assisted in writing the manuscript. GL, CDV, MT, EZ, MC, MF, and LCo undertook the experimental procedures. AE did the statistical analysis. All authors contributed to the article and approved the submitted version.

\section{FUNDING}

This work was partly supported by Fondi di Ricerca Locale, Università degli Studi di Torino, Torino, Italy; by Fondazione EMN Italy Onlus (Fondazione European Myeloma Network Italy Onlus), Torino, Italy; by Fondazione Cariplo (2015/0603); by Associazione Italiana per la Ricerca sul Cancro (IG 201821567); by Italian Ministry of Health (Bando Ricerca Finalizzata); and by Intramural Research Funding of Istituto Clinico Humanitas. EZ is a recipient of two fellowships from the Associazione Italiana per la Ricerca sul Cancro ("Nella Orlandini" 2018/2019-20870 and "Giancarlo Iuri Amadio" 2020-24051). CDV was a recipient of the post-doctoral fellowships from the Fondazione Umberto Veronesi (20171464, 2018-1974, 2019-2563).

\section{SUPPLEMENTARY MATERIAL}

The Supplementary Material for this article can be found online at: https://www.frontiersin.org/articles/10.3389/fimmu.2021. 816231/full\#supplementary-material

Regulated by $\alpha v$ Integrin and miR-100. Blood (2013) 121:3307-18. doi: 10.1182/blood-2012-07-442665

9. Crossland RE, Norden J, Juric MK, Green K, Pearce KF, Lendrem C, et al. Expression of Serum microRNAs Is Altered During Acute Graft-Versus-Host Disease. Front Immunol (2017) 8:308. doi: 10.3389/fimmu.2017.00308

10. McDonald GB, Tabellini L, Storer BE, Lawler RL, Martin PJ, Hansen JA. Plasma Biomarkers of Acute GVHD and Nonrelapse Mortality: Predictive Value of Measurements Before GVHD Onset and Treatment. Blood (2015) 126:113-20. doi: 10.1182/blood-2015-03-636753

11. Ponce DM, Hilden P, Mumaw C, Devlin SM, Lubin M, Giralt S, et al. High Day 28 ST2 Levels Predict for Acute Graft-Versus-Host Disease and Transplant-Related Mortality After Cord Blood Transplantation. Blood (2015) 125:199-205. doi: 10.1182/blood-2014-06-584789

12. Solán L, Kwon M, Carbonell D, Dorado N, Balsalobre P, Serrano D, et al. ST2 and REG $3 \alpha$ as Predictive Biomarkers After Haploidentical Stem Cell Transplantation Using Post-Transplantation High-Dose Cyclophosphamide. Front Immunol (2019) 10:2338. doi: 10.3389/fimmu.2019.02338

13. Zhao D, Kim Y-H, Greenson JK, Chaudhry MS, Hoepting M, Jeong S, et al. Regenerating Islet-Derived 3-Alpha (REG3A) Protects the Intestinal Stem Cell Niche to Control Acute Gastrointestinal Graft-Versus-Host Disease. Biol Blood Marrow Transplant (2018) 24:S69-70. doi: 10.1016/ j.bbmt.2017.12.614

14. Nagasawa M, Mitsuiki N, Yanagimachi M, Yamamoto M, Fukuda T, Miura O, et al. Utility of Novel T-Cell-Specific Extracellular Vesicles in Monitoring and Evaluation of Acute GVHD. Int J Hematol (2021) 113:910-20. doi: 10.1007/ s12185-021-03113-x 
15. Carneiro TX, Marrese DG, dos Santos MG, Gonçalves MV, Novis YS, Rizzatti EG, et al. Circulating Microparticles As Predictive Biomarkers of Acute Graft Versus Host Disease. Blood (2016) 128:5778-8. doi: 10.1182/blood. V128.22.5778.5778

16. Lia G, Di Vito C, Cerrano M, Brunello L, Calcaterra F, Tapparo M, et al. Extracellular Vesicles After Allogeneic Hematopoietic Cell Transplantation: Emerging Role in Post-Transplant Complications. Front Immunol (2020) 11:422. doi: 10.3389/fimmu.2020.00422

17. Zhang R, Wang X, Hong M, Luo T, Zhao M, Shen H, et al. Endothelial Microparticles Delivering microRNA-155 Into T Lymphocytes are Involved in the Initiation of Acute Graft-Versus-Host Disease Following Allogeneic Hematopoietic Stem Cell Transplantation. Oncotarget (2017) 8:23360-75. doi: 10.18632/oncotarget.15579

18. Ratajczak J, Miekus K, Kucia M, Zhang J, Reca R, Dvorak P, et al. Embryonic Stem Cell-Derived Microvesicles Reprogram Hematopoietic Progenitors: Evidence for Horizontal Transfer of mRNA and Protein Delivery. Leukemia (2006) 20:847-56. doi: 10.1038/sj.leu.2404132

19. Ratajczak J, Wysoczynski M, Hayek F, Janowska-Wieczorek A, Ratajczak MZ. Membrane-Derived Microvesicles: Important and Underappreciated Mediators of Cell-to-Cell Communication. Leukemia (2006) 20:1487-95. doi: $10.1038 /$ sj.leu.2404296

20. Shah R, Patel T, Freedman JE. Circulating Extracellular Vesicles in Human Disease. N Engl J Med (2018) 379:958-66. doi: 10.1056/NEJMra1704286

21. Lia G, Brunello L, Bruno S, Carpanetto A, Omedè P, Festuccia M, et al. Extracellular Vesicles as Potential Biomarkers of Acute Graft-vs-Host Disease. Leukemia (2018) 32:765-73. doi: 10.1038/leu.2017.277

22. Roberto A, Castagna L, Zanon V, Bramanti S, Crocchiolo R, McLaren JE, et al. Role of Naive-Derived T Memory Stem Cells in T-Cell Reconstitution Following Allogeneic Transplantation. Blood (2015) 125:2855-64. doi: 10.1182/blood-2014-11-608406

23. Plieskatt JL, Feng Y, Rinaldi G, Mulvenna JP, Bethony JM, Brindley PJ. Circumventing qPCR Inhibition to Amplify miRNAs in Plasma. Biomark Res (2014) 2:13. doi: 10.1186/2050-7771-2-13

24. Livak KJ, Schmittgen TD. Analysis of Relative Gene Expression Data Using Real-Time Quantitative PCR and the $2-\Delta \Delta$ ct Method. Methods (2001) 25:402-8. doi: 10.1006/meth.2001.1262

25. Gooley TA, Leisenring W, Crowley J, Storer BE. Estimation of Failure Probabilities in the Presence of Competing Risks: New Representations of Old Estimators. Stat Med (1999) 18:695-706. doi: 10.1002/(SICI)1097-0258 (19990330) 18:6<695::AID-SIM60>3.0.CO;2-O

26. Zhao X-S, Huang X-J. Seeking Biomarkers for Acute Graft-Versus-Host Disease: Where We Are and Where We Are Heading? Biomark Res (2019) 7:17. doi: 10.1186/s40364-019-0167-x

27. Lia G, Giaccone L, Leone S, Bruno B. Biomarkers for Early Complications of Endothelial Origin After Allogeneic Hematopoietic Stem Cell Transplantation: Do They Have a Potential Clinical Role? Front Immunol (2021) 12:641427. doi: 10.3389/fimmu.2021.641427

28. Giaccone L, Faraci DG, Butera S, Lia G, Di Vito C, Gabrielli G, et al. Biomarkers for Acute and Chronic Graft Versus Host Disease: State of the Art. Expert Rev Hematol (2021) 14:79-96. doi: 10.1080/17474086.2021. 1860001

29. Selmi C. Autoimmunity in 2011. Clin Rev Allergy Immunol (2012) 43:194206. doi: 10.1007/s12016-012-8330-2

30. Li W, Liu L, Gomez A, Zhang J, Ramadan A, Zhang Q, et al. Proteomics Analysis Reveals a Th17-Prone Cell Population in Presymptomatic GraftVersus-Host Disease. JCI Insight (2016) 1:e86660. doi: 10.1172/ jci.insight. 86660

31. Almici C, Skert C, Verardi R, Di Palma A, Bianchetti A, Neva A, et al. Changes in Circulating Endothelial Cells Count Could Become a Valuable Tool in the Diagnostic Definition of Acute Graft-Versus-Host Disease. Transplantation (2014) 98:706-12. doi: 10.1097/TP.0000000000000385

32. Yang J, Sundrud MS, Skepner J, Yamagata T. Targeting Th17 Cells in Autoimmune Diseases. Trends Pharmacol Sci (2014) 35:493-500. doi: 10.1016/j.tips.2014.07.006

33. Clement M, Fornasa G, Guedj K, Ben Mkaddem S, Gaston A-T, KhallouLaschet J, et al. CD31 Is a Key Coinhibitory Receptor in the Development of Immunogenic Dendritic Cells. Proc Natl Acad Sci (2014) 111:E1101-10. doi: 10.1073/pnas.1314505111
34. Marelli-Berg FM, Clement M, Mauro C, Caligiuri G. An Immunologist's Guide to CD31 Function in T-Cells. J Cell Sci (2013) 126:2343-52. doi: $10.1242 /$ jcs. 124099

35. Ma L, Mauro C, Cornish GH, Chai J-G, Coe D, Fu H, et al. Ig Gene-Like Molecule CD31 Plays a Nonredundant Role in the Regulation of T-Cell Immunity and Tolerance. Proc Natl Acad Sci (2010) 107:19461-6. doi: $10.1073 /$ pnas. 1011748107

36. Beer H-D, Longaker MT, Werner S. Reduced Expression of PDGF and PDGF Receptors During Impaired Wound Healing. J Invest Dermatol (1997) 109:132-8. doi: 10.1111/1523-1747.ep12319188

37. Ritchie D, Seconi J, Wood C, Walton J, Watt V. Prospective Monitoring of Tumor Necrosis Factor $\alpha$ and Interferon $\gamma$ to Predict the Onset of Acute and Chronic Graft-Versus-Host Disease After Allogeneic Stem Cell Transplantation. Biol Blood Marrow Transplant (2005) 11:706-12. doi: 10.1016/j.bbmt.2005.05.015

38. Levine JE. Implications of TNF- $\alpha$ in the Pathogenesis and Management of GVHD. Int J Hematol (2011) 93:571-7. doi: 10.1007/s12185-011-0803-1

39. Wall IB, Moseley R, Baird DM, Kipling D, Giles P, Laffafian I, et al. Fibroblast Dysfunction Is a Key Factor in the Non-Healing of Chronic Venous Leg Ulcers. J Invest Dermatol (2008) 128:2526-40. doi: 10.1038/jid.2008.114

40. Holler E, Kolb HJ, Möller A, Kempeni J, Liesenfeld S, Pechumer H, et al. Increased Serum Levels of Tumor Necrosis Factor Alpha Precede Major Complications of Bone Marrow Transplantation. Blood (1990) 75:1011-6. doi: 10.1182/blood.V75.4.1011.bloodjournal7541011

41. Huang X, Wan J, Lu D. Serum Tnfo Levels in Patients With Acute GraftVersus-Host Disease After Bone Marrow Transplantation. Leukemia (2001) 15:1089-91. doi: 10.1038/sj.leu.2402151

42. Hofmann S, Grasberger H, Jung P, Bidlingmaier M, Vlotides J, Janssen OE, et al. The Tumour Necrosis Factor-Alpha Induced Vascular Permeability is Associated With a Reduction of VE-Cadherin Expression. Eur J Med Res (2002) 7:171-6.

43. Colás-Algora N, García-Weber D, Cacho-Navas C, Barroso S, Caballero A, Ribas C, et al. Compensatory Increase of VE-Cadherin Expression Through ETS1 Regulates Endothelial Barrier Function in Response to Tnfo. Cell Mol Life Sci (2020) 77:2125-40. doi: 10.1007/s00018-019-03260-9

44. Dejana E. Endothelial Cell-Cell Junctions: Happy Together. Nat Rev Mol Cell Biol (2004) 5:261-70. doi: 10.1038/nrm1357

45. Vestweber D, Winderlich M, Cagna G, Nottebaum AF. Cell Adhesion Dynamics at Endothelial Junctions: VE-Cadherin as a Major Player. Trends Cell Biol (2009) 19:8-15. doi: 10.1016/j.tcb.2008.10.001

46. MacEwan DJ. TNF Ligands and Receptors - a Matter of Life and Death. $\mathrm{Br} J$ Pharmacol (2002) 135:855-75. doi: 10.1038/sj.bjp.0704549

47. Choi SW, Kitko CL, Braun T, Paczesny S, Yanik G, Mineishi S, et al. Change in Plasma Tumor Necrosis Factor Receptor 1 Levels in the First Week After Myeloablative Allogeneic Transplantation Correlates With Severity and Incidence of GVHD and Survival. Blood (2008) 112:1539-42. doi: 10.1182/ blood-2008-02-138867

48. Abdallah AN, Boiron JM, Attia Y, Cassaigne A, Reiffers J, Iron A. Plasma Cytokines in Graft vs Host Disease and Complications Following Bone Marrow Transplantation. Hematol Cell Ther (1997) 39:27-32. doi: 10.1007/ s00282-997-0027-2

49. August KJ, Chiang K-Y, Bostick RM, Flanders WD, Waller EK, Langston A, et al. Biomarkers of Immune Activation to Screen for Severe, Acute GVHD. Bone Marrow Transplant (2011) 46:601-4. doi: 10.1038/bmt.2010.165

50. Hawari FI, Rouhani FN, Cui X, Yu Z-X, Buckley C, Kaler M, et al. Release of Full-Length 55-kDa TNF Receptor 1 in Exosome-Like Vesicles: A Mechanism for Generation of Soluble Cytokine Receptors. Proc Natl Acad Sci (2004) 101:1297-302. doi: 10.1073/pnas.0307981100

51. Islam A, Jones H, Hiroi T, Lam J, Zhang J, Moss J, et al. cAMP-Dependent Protein Kinase A (PKA) Signaling Induces TNFR1 Exosome-Like Vesicle Release via Anchoring of PKA Regulatory Subunit Riiß to BIG2. J Biol Chem (2008) 283:25364-71. doi: 10.1074/jbc.M804966200

52. Chan KW, Hopke CD, Krams SM, Martinez OM. CD30 Expression Identifies the Predominant Proliferating T Lymphocyte Population in Human Alloimmune Responses. J Immunol (2002) 169:1784-91. doi: 10.4049/ jimmunol.169.4.1784

53. Blazar BR, Levy RB, Mak TW, Panoskaltsis-Mortari A, Muta H, Jones M, et al. CD30/CD30 Ligand (CD153) Interaction Regulates CD4 + T Cell-Mediated 
Graft-Versus-Host Disease. J Immunol (2004) 173:2933-41. doi: 10.4049/ jimmunol.173.5.2933

54. Chen Y-B, McDonough S, Hasserjian R, Chen H, Coughlin E, Illiano C, et al. Expression of CD30 in Patients With Acute Graft-Versus-Host Disease. Blood (2012) 120:691-6. doi: 10.1182/blood-2012-03-415422

55. Thompson M, Ohnuma K, Abe M, Morimoto C, Dang N. CD26/Dipeptidyl Peptidase IV as a Novel Therapeutic Target for Cancer and Immune Disorders. Mini-Reviews Med Chem (2007) 7:253-73. doi: 10.2174/ 138955707780059853

56. Fox DA, Hussey RE, Fitzgerald KA, Acuto O, Poole C, Palley L, et al. Ta1, a Novel 105 KD Human T Cell Activation Antigen Defined by a Monoclonal Antibody. J Immunol (1984) 133:1250-6.

57. Morimoto C, Torimoto Y, Levinson G, Rudd CE, Schrieber M, Dang NH, et al. 1F7, a Novel Cell Surface Molecule, Involved in Helper Function of CD4 Cells. J Immunol (1989) 143:3430-9.

58. Dang NH, Torimoto Y, Sugita K, Daley JF, Schow P, Prado C, et al. Cell Surface Modulation of CD26 by Anti-1F7 Monoclonal Antibody. Analysis of Surface Expression and Human T Cell Activation. J Immunol (1990) 145:3963-71.

59. Ohnuma K, Dang NH, Morimoto C. Revisiting an Old Acquaintance: CD26 and its Molecular Mechanisms in T Cell Function. Trends Immunol (2008) 29:295-301. doi: 10.1016/j.it.2008.02.010

60. Hatano R, Ohnuma K, Yamamoto J, Dang NH, Yamada T, Morimoto C. Prevention of Acute Graft-Versus-Host Disease by Humanized Anti-CD26 Monoclonal Antibody. Br J Haematol (2013) 162:263-77. doi: 10.1111/bjh.12378

61. Bengsch B, Seigel B, Flecken T, Wolanski J, Blum HE, Thimme R. Human Th17 Cells Express High Levels of Enzymatically Active Dipeptidylpeptidase IV (Cd26). J Immunol (2012) 188:5438-47. doi: 10.4049/jimmunol.1103801

62. Hildebrandt M, Rose JR M. Dipeptidyl Peptidase IV (DP IV, CD26) in Patients With Inflammatory Bowel Disease. Scand J Gastroenterol (2001) 36:1067-72. doi: 10.1080/003655201750422675

63. Sromova L, Busek P, Sedova L, Sedo A. Intraindividual Changes of Dipeptidyl Peptidase-IV in Peripheral Blood of Patients With Rheumatoid Arthritis are Associated With the Disease Activity. BMC Musculoskelet Disord (2015) 16:244. doi: 10.1186/s12891-015-0707-y

64. Zitzer NC, Snyder K, Meng X, Taylor PA, Efebera YA, Devine SM, et al. MicroRNA-155 Modulates Acute Graft-Versus-Host Disease by Impacting T Cell Expansion, Migration, and Effector Function. J Immunol (2018) 200:4170-9. doi: 10.4049/jimmunol.1701465
65. Johansson K, Malmhäll C, Ramos-Ramírez P, Rådinger M. MicroRNA-155 is a Critical Regulator of Type 2 Innate Lymphoid Cells and IL-33 Signaling in Experimental Models of Allergic Airway Inflammation. J Allergy Clin Immunol (2017) 139:1007-16.e9. doi: 10.1016/j.jaci.2016.06.035

66. Ferrara JLM, Harris AC, Greenson JK, Braun TM, Holler E, Teshima T, et al. Regenerating Islet-Derived 3-Alpha is a Biomarker of Gastrointestinal GraftVersus-Host Disease. Blood (2011) 118:6702-8. doi: 10.1182/blood-2011-08375006

67. Deregibus MC, Figliolini F, D'antico S, Manzini PM, Pasquino C, De Lena M, et al. Charge-Based Precipitation of Extracellular Vesicles. Int J Mol Med (2016) 38:1359-66. doi: 10.3892/ijmm.2016.2759

68. Helwa I, Cai J, Drewry MD, Zimmerman A, Dinkins MB, Khaled ML, et al. A Comparative Study of Serum Exosome Isolation Using Differential Ultracentrifugation and Three Commercial Reagents. PloS One (2017) 12: e0170628. doi: 10.1371/journal.pone.0170628

69. Patel GK, Khan MA, Zubair H, Srivastava SK, Khushman M, Singh S, et al. Comparative Analysis of Exosome Isolation Methods Using Culture Supernatant for Optimum Yield, Purity and Downstream Applications. Sci Rep (2019) 9:5335. doi: 10.1038/s41598-019-41800-2

Conflict of Interest: The authors declare that the research was conducted in the absence of any commercial or financial relationships that could be construed as a potential conflict of interest.

Publisher's Note: All claims expressed in this article are solely those of the authors and do not necessarily represent those of their affiliated organizations, or those of the publisher, the editors and the reviewers. Any product that may be evaluated in this article, or claim that may be made by its manufacturer, is not guaranteed or endorsed by the publisher.

Copyright (c) 2022 Lia, Di Vito, Bruno, Tapparo, Brunello, Santoro, Mariotti, Bramanti, Zaghi, Calvi, Comba, Fasci, Giaccone, Camussi, Boyle, Castagna, Evangelista, Mavilio and Bruno. This is an open-access article distributed under the terms of the Creative Commons Attribution License (CC BY). The use, distribution or reproduction in other forums is permitted, provided the original author $(s)$ and the copyright owner(s) are credited and that the original publication in this journal is cited, in accordance with accepted academic practice. No use, distribution or reproduction is permitted which does not comply with these terms. 